Nutr. Metabol. 1972;14:127

\title{
Buchbesprechung - Book Review - Livre nouveau
}

V. N. Patwardhan and W. J. Darby: The State of Nutrition in the Arab Middle East. Vanderbilt University Press, Nashville 1972. XII + 308 pp. US\$ 15.-.

Both of the principal authors have an outstanding experience in the nutritional problems and deficiency diseases in tropical countries. Patwardhan served many years as Director of the Nutrition Research Laboratories of the Indian Council of Medical Research in Coonor and Hyderabad, he then became Chief of the Nutrition Unit, WHO in Geneva. After his resignation he returned to an almost tropical country, Egypt, being simultaneously Professor of Nutrition, Vanderbilt University and Head of the Nutrition Department of US Naval Medical Research Unit in Cairo. Here he collaborated closely with W.J. Darby, Director of the Division of Nutrition of Vanderbilt University, School of Medicine.

Only scientists such as these, having an enormous knowledge in and of the countries they are dealing with, are able to write so interesting and outstanding contributions to the nutritional situation. Their description of the occurrence of deficiency diseases like pellagra, nutritional anemia, endemic goiter, etc. includes the history of nutrition research and the food habits of the people. Most important are the interdisciplinary views of all nutritional problems. The book, which makes fascinating reading, is a basis for everyone who wants to study the nutritional situation in developing countries and to find ways and means to improve it. H.-D. Cremer, Giessen 